Int. J. Electrochem. Sci., 14 (2019) 9112 - 9121

International Journal of

ELECTROCHEMICAL

SCIENCE

$\underline{\text { www.electrochemsci.org }}$

Short Communication

\title{
Antimony-doped $\mathrm{SnO}_{2}$ hollow nanospheres as negative materials for high-performance lithium-ion batteries
}

\author{
Sai Wang ${ }^{1}$, Jianxiong Liu', Xiaohua Yu ${ }^{1}$, Yingjie Zhang ${ }^{1,2}$, Jiaming Liu', Zhongren Zhong ${ }^{2}$, \\ Zhaolin Zhan ${ }^{1}$, Mingyu Zhang ${ }^{4}$, Xi Yang ${ }^{4}$, Peng Dong, ,* Yannan Zhang, ${ }^{2, *}$ \\ ${ }^{1}$ Faculty of Materials Science and Engineering, Kunming University of Science and Technology, \\ Kunming 650093, China \\ ${ }^{2}$ National and Local Joint Engineering Laboratory for Lithium-ion Batteries and Materials Preparation \\ Technology, Key Laboratory of Advanced Battery Materials of Yunnan Province, Faculty of \\ Metallurgical and Energy Engineering, Kunming University of Science and Technology, Kunming \\ 650093, China \\ ${ }^{3}$ School of Metallurgy Engineering, Jiangxi University of Science and Technology, Ganzhou 341000, \\ China \\ ${ }^{4}$ Yunnan Provincial Energy Research Institute Co., LTD., Kunming 650093, China \\ *E-mail: dongpeng2001@ 126.com (Peng Dong), zyn_legolas@163.com (Yannan Zhang)
}

doi: $10.20964 / 2019.09 .78$

Received: 13 May 2019 / Accepted: 8 July 2019 / Published: 5 August 2019

$\mathrm{SnO}_{2}$-based lithium-ion batteries suffer from capacity fades rapidly during lithiation and delithiation at high current density due to the aggregation and cracking of active materials. This work proposes a novel architecture of antimony-doped $\mathrm{SnO}_{2}$ (ATO) hollow nanospheres using hydrothermal and hard template methods. The crystal structure, morphology, and surface elemental composition of ATO are tested by XRD, SEM TEM and XPS, respectively. Notably, the electrochemical tests results indicate that the ATO negative materials exhibit a significantly improved cycling and rate performance than that pure hollow $\mathrm{SnO}_{2}$ nanospheres. After 100 cycles, ATO still maintains a high capacity retention of $709 \mathrm{mAh} \mathrm{g}^{-1}$ at 0.1 $\mathrm{A} \mathrm{g}^{-1}$ and delivers $286 \mathrm{mAh} \mathrm{g}^{-1}$ even at $5 \mathrm{~A} \mathrm{~g}^{-1}$. These consequences reveal that the $\mathrm{Sb}$ modified $\mathrm{SnO}_{2}$ hollow sphere electrodes have good implications for the design of high-power-density negative materials of the next-generation lithium-ion batteries.

Keywords: Lithium-ion batteries; $\mathrm{SnO}_{2}$ hollow nanospheres; Antimony-doped; High rate performance

\section{$\underline{\text { FULL TEXT }}$}

(C) 2019 The Authors. Published by ESG (www.electrochemsci.org). This article is an open access article distributed under the terms and conditions of the Creative Commons Attribution license (http://creativecommons.org/licenses/by/4.0/). 